\title{
O PROCESSO DE INCLUSÃO DE UMA ALUNA DEFICIENTE INTELECTUAL EM UMA ESCOLA COMUM DO ENSINO FUNDAMENTAL I
}

\author{
THE PROCESS OF INCLUSION OF A STUDENT INTELLECTUAL DISABILITY \\ IN A COMMON SCHOOL ELEMENTARY SCHOOL I
}

\author{
Camila Lourenço MORGADO ${ }^{i}$ \\ Sílvio Henrique FISCARELLI ${ }^{\text {ii }}$
}

RESUMO: Diante das políticas educacionais que preconizam uma educação inclusiva que respeite e valorize todos os alunos, independentemente de suas características individuais, desenvolvemos um estudo para verificar como esse cenário é visto por um professor de escola comum que atua com um aluno com deficiência intelectual no Ensino Fundamental I. Para tanto utilizamos uma abordagem qualitativa de pesquisa, como procedimento metodológico o Estudo de Caso e a entrevista semiestruturada como instrumento de coleta de dados. O objetivo foi analisar as concepções por parte do professor acerca da profissão docente, da inclusão, o auxílio por parte da equipe gestora e do AEE, concepção de aprendizagem do aluno com deficiência e o contato com a família. Os dados mostraram que muitos avanços foram alcançados no âmbito legal no que diz respeito a inclusão dos alunos com deficiência na escola comum, porém a realidade da sala de aula ainda é bastante precária, o que dificulta a inclusão efetiva dos alunos com deficiência.

PALAVRAS-CHAVE: Inclusão Escolar. Ensino Fundamental I. Deficiência Intelectual. Profissão Docente.

ABSTRACT: Faced with the educational policies that advocate inclusive education that respects and values all students, regardless of their individual characteristics, we developed a study to see how this scenario is seen by a professor of regular school that works with a student with intellectual disabilities in Elementary Education I. for this we used a qualitative research approach, as methodological approach the case study and semi-structured interviews as a data collection instrument. The aim was to analyze the concepts by the teacher on the teaching profession, including the assistance by the management team and the ESA, design student learning disabled and the contact with the family. The data showed that many advances have been achieved in the legal framework regarding the inclusion of students with disabilities in regular schools, but the reality of the classroom is still fragile, which makes the effective inclusion of students with disabilities.

KEYWORDS: School inclusion. Elementary school. Intellectual disabilities. Teaching profession. 


\section{Introdução}

De acordo com Silva-Porta (2015), ao longo da história, a Educação Especial estabeleceu uma política segregatória para as pessoas público-alvo dessa modalidade de ensino, uma vez que sempre foi vista como uma modalidade paralela ao ensino regular. Os alunos da educação especial eram escolarizados em ambientes separados, classes especiais e escolas especializadas, possuíam currículos paralelos, propostas pedagógicas reabilitadoras, vinculadas ao campo médico, com pouca atenção às questões pedagógicas.

Silva (2015), afirma que no século XIX os serviços de Educação Especial tiveram início no Brasil, com ideias de implementação de ações que visavam atender pessoas com deficiência intelectual e física, tal modelo foi inspirado em experiências estadunidenses e europeias. Porém, tais iniciativas ainda não estavam incluídas nas políticas públicas brasileiras, sendo assim, precisou-se esperar aproximadamente um século para que a Educação Especial estivesse presente no sistema educacional nacional.

Ainda de acordo com Silva (2015), apenas nos anos 1960 a Educação Especial foi instituída oficialmente como modalidade de ensino e denominada "Educação dos Excepcionais". Mantoan (2008), aponta que a Educação Especial no país pode ser dividida em três grandes períodos, de 1954 a 1956, com iniciativas de caráter essencialmente privado, de 1957 a 1993, com ações oficiais de âmbito nacional e após 1993, (onde) ocorre o nascimento de movimentos a favor da Educação Especial.

Silva (2015), afirma que a criação de instituições que ofereciam assistência aos deficientes se deu ao longo desse tempo, sendo que, em 1957, a Educação Especial foi assumida pelo poder público a partir da criação de campanhas, com o intuito de atender cada uma das deficiências. O Ministério da Educação e Cultura (MEC) instituiu, em 1972, o grupo tarefa de Educação Especial em conjunto com James Gallagher, apresentando assim a primeira proposta de Educação Especial Brasileira.

A Lei de Diretrizes e Bases da Educação Nacional (LDB) de 1961, apresenta em seu texto o direito de crianças excepcionais ao sistema convencional de ensino, assim como várias leis que foram promulgadas a seguir. Porém, tais regulamentações sempre utilizaram o termo preferencialmente, o que permitiu a interpretação por parte de gestores e educadores de que alunos com necessidades especiais deveriam frequentar 
escolas especiais, pois não possuíam condições de cursar a escola regular (WISCH, 2013).

De acordo com Wisch (2013), a Constituição Federal de 1988, em seu artigo 208, utiliza novamente o termo preferencialmente ao tratar dos alunos público-alvo da educação especial e do atendimento educacional especializado, assim, pouco se avança em relação a inclusão na escola regular.

Wisch (2013), aponta ainda documentos internacionais que exerceram influência na elaboração de políticas públicas para a educação especial no Brasil, como a Conferência de Educação para Todos (1990) e a Declaração de Salamanca (1994). Em 1994 foi publicada no Brasil a Política Nacional de Educação Especial, afirmando que, sempre que o aluno possuísse condições de acompanhar as aulas em escolas regulares, estes deveriam ser integrados a estas escolas. Contudo, tal iniciativa não possibilitou aos alunos condições de aprendizagem, conforme constatado pelo próprio MEC, pois a responsabilidade de adaptação aos conteúdos da escola ficava por conta dos estudantes integrados.

Segundo Wisch (2013), a partir da Lei de Diretrizes e Bases da Educação Nacional (LDB) de 1996, em seu artigo 59, a educação especial passa a ganhar maior espaço, definindo que as escolas devem oferecer currículos adaptados, assim como recursos e métodos que atendam às necessidades dos alunos, além de assegurar a terminalidade específica e a aceleração.

A partir da LDB de 1996, foram elaboradas diversas leis e resoluções no âmbito da educação especial, como a Resolução CNE/CEB nº 2/2001, que instituiu Diretrizes Nacionais para a Educação Especial na Educação Básica, determinando que as escolas devem se organizar para atender os educandos com necessidades especiais. O Plano Nacional de Educação - PNE, Lei $n^{\circ}$ 10.172/2001, estabelece objetivos e metas para que os sistemas de ensino possam favorecer o atendimento as necessidades especiais dos alunos. O Programa Educação Inclusiva, criado pelo MEC em 2003, teve como objetivo a formação continuada de gestores e educadores capazes de oferecer educação especial na perspectiva da educação inclusiva. Em 2007, o Plano de Desenvolvimento da Educação - PDE foi criado para garantir a valorização das individualidades e aprendizagem dos educandos. No mesmo ano surge a Política Nacional de Educação Especial, com uma perspectiva inclusiva, definindo com clareza a importância da inclusão na escola regular, garantiu o atendimento educacional especializado, salas de recursos multifuncionais para as escolas com educandos incluídos e investimento em 
formação docente, tornando assim, a inclusão obrigatória na escola regular (WISCH, 2013).

Outro marco de extrema importância em relação a educação especial, a fim de atender a Política Nacional de Educação Especial na Perspectiva da Inclusão (2008), foi o Decreto $n^{\circ}$ 6.571/2008, tendo como ponto principal reafirmar a educação especial como não substitutiva à escolarização no ensino regular, garantindo assim que os educandos em uma escola inclusiva tenham efetivado o direito, concomitantemente, ao ensino comum e ao atendimento especializado.

O Parecer CNE-CEB n 13/2009 dispõe a respeito das Diretrizes Operacionais para o Atendimento Educacional Especializado na Educação Básica, modalidade da Educação Especial, determinando que o Atendimento Educacional Especializado (AEE) seja realizado na sala de recursos multifuncionais da própria escola, em outra de ensino regular, ou em centros especializados, no turno inverso da escolarização regular, não substituindo as aulas comuns. Tal Parecer trouxe também como ponto importante, a partir de 2010, que os alunos da educação especial passariam a ser contabilizados duplamente pelo FUNDEB (Fundo de Manutenção e Desenvolvimento da Educação Básica e de Valorização dos Profissionais da Educação), se matriculados em classes do ensino regular e no atendimento educacional especializado, considerando assim, a necessidade de recursos adicionais para essa escolarização.

Ainda de acordo com Wisch (2013), a Política Nacional de Educação Especial na Perspectiva Inclusiva, assim como o decreto e parecer seguintes, trouxe avanços significativos no âmbito da inclusão, porém, alguns pontos desta política geraram questionamentos e críticas, principalmente a respeito das escolas especiais, que não foram contempladas, e à obrigatoriedade do laudo médico para a matrícula no AEE.

Em 2011, o Decreto 7.611/2011 revoga o Decreto 6.571/2008, trazendo orientações mais gerais e amplas a respeito da educação especial, em que classes e escolas especiais, assim como as salas de recursos multifuncionais, são consideradas, acatando a existência de tal modalidade de ensino. O Pacto Nacional pela Alfabetização na Idade Certa, lançado em 2012, oferece aos professores alfabetizadores formação para garantir a todos os educandos a alfabetização até os oito anos de idade, além de oferecer grande ênfase no direito de aprendizagem das crianças incluídas.

A Lei $n^{\circ} 13.146$, de 6 de julho de 2015, institui a Lei Brasileira de Inclusão da Pessoa com Deficiência, que traz como pontos principais sobre a educação a proibição das instituições de ensino privadas de cobrar a mais de alunos com deficiência, reserva 
de $10 \%$ das vagas em instituições de ensino superior ou profissional, além de obrigar o poder público a fomentar a publicação de livros acessíveis pelas editoras.

Apesar dos avanços que podemos detectar com a promulgação dos vários decretos, pareceres e leis, a realidade das escolas brasileiras ainda é bastante precária em relação ao atendimento de educandos da educação especial. A proposta deste artigo é analisar uma entrevista semiestruturada, realizada com um professor do Ensino Fundamental I, que possui um aluno com deficiência intelectual, buscando verificar quais as dificuldades enfrentadas no cotidiano escolar e os auxílios oferecidos pela equipe gestora da escola.

\section{Metodologia}

Este estudo seguiu uma abordagem qualitativa de pesquisa e teve como procedimento metodológico o Estudo de Caso, usando como instrumento uma entrevista semiestruturada aplicada a um professor do Ensino Fundamental I que atuava com um aluno com deficiência intelectual em sua sala de aula, analisando as dificuldades enfrentadas durante o processo de ensino e aprendizagem e o auxílio da equipe gestora.

De acordo com Lüdke e André (1986), a pesquisa qualitativa pode se desenvolver em três períodos, a exploração, a decisão e a descoberta. O período de exploração condiz com a seleção e a observação dos problemas, buscando o ganho de maior conhecimento sobre o acontecimento e a seleção de quais aspectos serão mais profundamente analisados. A segunda etapa diz respeito à sistematização dos dados por parte do pesquisador, procurando uma compreensão cada vez maior do fenômeno estudado. O último período é a busca da explicação do acontecimento que representa a realidade na tentativa de encaixar suas principais características a uma visão mais amplificada.

Lüdke e André (1986), afirmam que os estudos de caso visam a descoberta, com a possibilidade de acréscimo de novos aspectos, elementos e dimensões ao longo do estudo, enfatizando a interpretação em contexto, retratando a realidade de forma complexa e profunda, procurando retratar os diferentes e conflitantes pontos de vista presentes em uma situação social. Os estudos de caso contam ainda com três fases, de acordo com as autoras, sendo a primeira aberta ou exploratória, a segunda mais 
sistemática e de coleta de dados e a terceira a análise e interpretação sistemática dos dados.

Para Lüdke e André (1986), a entrevista é um instrumento básico para a coleta de dados, não apresenta uma relação hierárquica entre pesquisador e pesquisado, criando uma relação de interação, (e) uma atmosfera de influência recíproca entre quem pergunta e quem responde. A entrevista tem como vantagem sobre outras técnicas a captação corrente e imediata da informação, sobre diversos tópicos e de qualquer tipo de informante. Os esquemas mais livres e menos estruturados são considerados mais adequados para a pesquisa em educação, pois permitem uma maior liberdade de percurso, sendo mais convenientemente abordáveis no contato com professores, alunos, diretores, orientadores e pais.

A partir desta metodologia pretende-se analisar a inclusão de um aluno com deficiência intelectual em uma sala de aula regular, localizada em uma escola do Ensino Fundamental I, a partir da perspectiva do professor, relatando suas dificuldades e auxílios recebidos em seu cotidiano, durante o processo de ensino e aprendizagem.

\section{Análise de dados}

A entrevista semiestruturada a ser analisada foi realizada com um professor do Ensino Fundamental I, com cerca de um ano de experiência na profissão, formado em Licenciatura Plena em Pedagogia, com uma aluna com deficiência intelectual em uma escola de periferia de uma cidade no interior do estado de São Paulo.

Para uma análise mais completa do conteúdo da entrevista, foram criadas cinco categorias de análise, buscando organizar e analisar de maneira mais ampla o conteúdo das respostas dadas pelo professor a cada uma das 12 questões propostas previamente. As categorias de análise propostas são: Concepção acerca da profissão docente, Concepção acerca da inclusão, Auxílio por parte da equipe gestora e do AEE, Concepção de aprendizagem do aluno com deficiência, Contato com a família.

\section{Concepção acerca da profissão docente}


A primeira questão realizada durante a entrevista foi sobre a visão do professor entrevistado a respeito de sua concepção acerca da profissão docente, buscando identificar a forma como o profissional se enxerga inserido dentro de suas funções. Considerando a resposta do professor podemos destacar a seguinte passagem:

\begin{abstract}
"Para mim, ser professor é auxiliar no desenvolvimento das pessoas, sendo ela não somente no campo acadêmico com os saberes historicamente construídos, mas como pessoas e que elas entendam onde e como elas estão inseridas em um contexto maior, sendo que elas são peças importantes, não devendo ficar paradas e aceitando o que uma sociedade opressora impõem."
\end{abstract}

De acordo com a resposta dada podemos inferir que o professor entrevistado não se enxerga apenas como o profissional responsável por transmitir conteúdo para seus alunos, mas que também se preocupa com sua formação humana enquanto cidadão. A partir dessa concepção de formador que o professor explicita em sua resposta podemos compreender que este entende seu aluno como um sujeito ativo no processo de ensino e aprendizagem, capaz de possuir suas próprias concepções e visões de mundo, que podem ir muito além dos conteúdos aprendidos dentro de sala de aula.

\title{
Concepção acerca da inclusão
}

Como segunda categoria de análise da entrevista destaca-se a concepção do professor sobre a inclusão de sua aluna com deficiência intelectual em uma sala de aula regular, assim como sua visão acerca da inclusão escolar de maneira mais ampla.

Podemos destacar na resposta do professor entrevistado as seguintes passagens a respeito de sua concepção sobre o processo de inclusão:

\footnotetext{
"Acho que devemos pensar que o atendimento deve ser pensado em cada caso, mas sempre devendo imperar o atendimento em sala de aula, pois em vários casos, como nesse, a socialização do indivíduo é benéfica por aprender muito mais com os companheiros além da inserção a um mundo maior. Não descartando quando necessário o atendimento educacional fora da sala (no caso estudado, ela possuía 2 aulas semanais com uma professora especialista)".

"Concordo com a inclusão de alunos deficientes nas salas de aulas, já tive alunos no pouco tempo de sala que trabalhei com as mais diversas deficiências, desde paralisia cerebral, baixa visão, TDAH,
} 
entre outras e todas elas necessitam de no mínimo a socialização para poder melhorar como pessoa e aluno."

Analisando a resposta dada pelo professor é possível perceber que sua concepção a respeito da inclusão de alunos deficientes em salas de aula regular vai além da apreensão por parte do educando dos conteúdos historicamente valorizados. De acordo com o professor, os alunos que fazem parte do processo de inclusão escolar, precisam ser vistos além de suas capacidades cognitivas. Para o entrevistado, muitos alunos se encontram em um grau de comprometimento cognitivo muito alto, porém isso não impede sua socialização e sua capacidade de ampliar sua visão de mundo por meio de sua inserção em sala de aula e do convívio com outras crianças.

\section{Auxílio por parte da equipe gestora e do AEE}

A respeito do auxílio dado ao professor por parte da equipe gestora da escola no processo de inclusão da aluna deficiente em sala de aula, podemos destacar primeiramente a forma como a notícia chegou até o professor, até a ajuda fornecida pela escola para a adaptação física e curricular da escola, além do auxílio no cotidiano dentro de sala de aula.

A forma como o professor recebeu a notícia de que possuiria em sua sala uma aluna do processo de inclusão pode ser destacada nas seguintes passagens:

\footnotetext{
"Tomei conhecimento de tal informação logo depois que ela foi rematriculada, pois ela já era aluna da escola, mas por não conseguir acompanhar ficou 1 ano fora da escola, retornando por questões de bolsas de ajuda (bolsa família). Minha reação foi a mais tranquila possível, pois mesmo na época de estágio e por questões familiares, já convivi com deficiências piores. Outra reação foi pedir auxílio logo de imediato para a coordenadora pedagógica para me auxiliar".

"As informações foram levadas a mim pelo diretor pelo fato da escola ser muito pequena (5 classes por turno) e ter um número reduzido de professores, informações estas sobre como andava o desenvolvimento dela, as dificuldades familiares que enfrentavam (os alunos da escola eram majoritariamente oriundos de uma comunidade carente que havia se desenvolvido a poucos anos), algumas ideias de como trabalhar com ela, para que não houvesse um deslocamento dela em relação a turma e em relação as dificuldades que ela apresenta, como o baixo desenvolvimento da fala, organização de ideias em nível rudimentar e letramento ainda em fase inicial."
} 
É possível perceber que a presença da aluna deficiente em sala de aula não foi uma surpresa para o professor, a equipe gestora se preocupou em manter o docente informado a respeito do histórico da aluna em relação a sua deficiência e trajetória escolar. Também podemos afirmar que houve uma abertura por parte da equipe gestora para que o professor pudesse recorrer ao seu auxílio sempre que fosse preciso, devido ao desenvolvimento cognitivo muito baixo alcançado pela aluna até o momento.

Ainda a respeito do auxílio da gestão da escola em relação ao processo de ensino e aprendizagem da aluna em sala de aula, podemos destacar na resposta do professor o seguinte:

"A gestão me auxiliou na construção de um material que melhor se enquadrasse, e com o auxílio, quando possível, de um professor para ajudar. Pois mesmo a escola sendo pequena, possuía casos muito mais complicados que necessitavam de um maior acompanhamento".

"No caso não foi necessário uma mudança curricular e nem adaptações físicas, somente adaptações e em alguns momentos troca de material."

Neste caso, podemos comprovar que a gestão da escola ofereceu auxílio para o professor, dentro das possibilidades da escola, para a construção especial de materiais, além da ajuda de um professor auxiliar em certos momentos.

Sobre o AEE oferecido para a aluna, podemos destacar a seguinte passagem na resposta do entrevistado:

\footnotetext{
"Nesse caso, ela recebeu atendimento na escola. Não tendo em outros lugares por não haver um diagnóstico de uma entidade responsável, mesmo a escola dando encaminhamentos no caso. A professora especialista nos auxiliava quando necessário e também a coordenadora."
}

Segundo o relato do professor, a aluna foi diagnosticada como deficiente intelectual pelos profissionais presentes na escola e, apesar de ter recebido encaminhamento e orientação para a procura de um atendimento especializado, seus responsáveis ainda não haviam procurado o atendimento adequado. Porém, a escola contava com uma profissional especializada em educação especial, que oferecia o auxílio possível para que a aluna pudesse alcançar seu desenvolvimento cognitivo dentro de suas possibilidades, por meio da adaptação dos materiais oferecidos pela escola. 
A respeito do convívio dentro de sala de aula, destaca-se a seguinte passagem:

"Mesmo a aluna tendo uma linguagem quase incompreensivel $e$ outras questões complicadas, ela possuía uma boa interação com os alunos da escola inteira e outros professores e servidores."

O entrevistado destaca a dificuldade de comunicação enfrentada durante o convívio em sala de aula, (e) tal situação certamente é dificultadora no processo de ensino e aprendizagem. Porém, o professor destaca que outras estratégias de comunicação foram alcançadas, buscando superar esta dificuldade e auxiliar no desenvolvimento cognitivo da aluna.

\section{Concepção de aprendizagem do aluno com deficiência}

A respeito da concepção de aprendizagem do aluno com deficiência por parte do professor entrevistado, podemos perceber sua visão da aprendizagem como algo além do desenvolvimento cognitivo da criança, do ponto de vista de deficiências com um grau de comprometimento mais alto.

A partir do depoimento do professor, podemos destacar um ponto bastante esclarecedor a respeito de sua concepção em relação a aprendizagem da sua aluna, quando é questionado sobre se sua aprendizagem é ou não satisfatória:

\footnotetext{
"Não, dependendo da deficiência o aluno somente passa pela escola, ainda mais em uma escola com sérias dificuldades. Mas como socialização e várias outras questões, foram muito relevantes os avanços que proporciona o ensino diferenciado."
}

Podemos perceber que o professor considera que muitos alunos do processo de inclusão, não alcançarão uma aprendizagem considerada satisfatória pelos padrões atuais da sociedade, considerando seu desenvolvimento cognitivo e capacidade de apreensão dos conhecimentos socialmente construídos e valorizados. No entanto, este considera que a socialização e a inserção do aluno na escola é um processo extremamente importante no seu desenvolvimento como ser humano, buscando sempre alcançar a máxima autonomia possível, tanto em seu dia a dia como em sua capacidade de raciocínio. 


\section{Contato com a família}

A última categoria de análise apresentada neste estudo trata do contato entre o professor e a equipe gestora com a família da aluna com deficiência, buscando evidenciar o diálogo entre essas duas esferas, que se apresenta como algo essencial para o desenvolvimento de um trabalho educativo de qualidade.

Desta forma, podemos destacar a seguinte passagem na fala do professor entrevistado:

"Não possuía um contato com a família dessa aluna, somente a direção conversava com a família, por questões de horário. Mas o pouco que possuía, podemos ver que a educação escolar não é prioridade, por diversas outras questões mais importantes a sua subsistência."

Nesta fala do professor fica claro que as condições de vida da família de sua aluna com deficiência são bem precárias, o que acaba impedindo um maior contato entre os profissionais da escola e seus responsáveis, dificultando o desenvolvimento de uma relação que certamente seria benéfica para a aprendizagem da aluna. Portanto, pode-se considerar que o apoio oferecido ao professor era, quase exclusivamente, por parte da equipe gestora da escola e da profissional especializada na adaptação de materiais.

\section{Conclusão}

A partir da retrospectiva histórica realizada por meio das principais leis, pareceres e resoluções a respeito da inclusão de pessoas com deficiência no ensino regular e da análise da entrevista realizada com um professor do Ensino Fundamental I, que possui uma aluna com deficiência em sua sala de aula, podemos concluir que muitos avanços foram alcançados no âmbito legal no que diz respeito a inclusão dos alunos com deficiência, porém, a realidade da sala de aula ainda é bastante precária.

A análise do relato do professor entrevistado demonstra que muitas escolas ainda não possuem os devidos recursos para atender crianças com necessidades especiais, $\mathrm{o}$ que acaba reduzindo o trabalho do professor em uma simples adaptação dos materiais já 
existentes, o que pode muitas vezes não ser totalmente adequado para as necessidades especificas de cada aluno. A presença de um profissional especializado colabora para a adaptação da realidade escolar e para que o professor comum possa se preparar para receber o aluno com deficiência em sua sala de aula, mas esse profissional muitas vezes se encontra em uma situação de sobrecarga de trabalho, dificultando assim sua atuação profissional.

Contudo, podemos perceber uma mudança de concepção acerca da inclusão de alunos com deficiência no ensino regular, a partir do momento em que os profissionais passam a compreender de forma mais profunda a intenção de tal processo. $O$ profissional da área da educação entrevistado neste estudo, demonstra esta compreensão, quando afirma que o espaço escolar pode colaborar para um desenvolvimento que vai além do grau cognitivo de seus alunos, mesmo quando estes apresentam um grau maior de comprometimento devido a sua deficiência. Sendo assim, podemos concluir que a escola regular pode oferecer novos horizontes para seus alunos deficientes, ampliando sua autonomia e seu desenvolvimento cognitivo.

\section{Referências}

BRASIL. Decreto $\mathrm{n}^{\mathrm{o}}$ 6.571, de 17 de setembro de 2008. Dispõe sobre o atendimento educacional especializado, regulamenta o parágrafo único do art. 60 da Lei no 9.394, de 20 de dezembro de 1996, e acrescenta dispositivo ao Decreto no 6.253, de 13 de novembro de 2007. Diário Oficial da União, Brasília, DF, 18 de set. 2008. Disponível em: <http://www.planalto.gov.br/ ccivil_03/_ato20072010/2008/Decreto/D6571impressao.htm>. Acesso em: 10 maio 2016.

. Ministério da Educação. Conselho Nacional de Educação. Parecer CNE/CEB No 13/2009. Estabelece diretrizes operacionais para $\mathrm{O}$ atendimento educacional especializado na Educação Básica, modalidade Educação Especial. Diário Oficial da União, Brasília, DF, jun., 2009. Disponível em: <http://portal.mec.gov.br/dmdocuments/ pceb013_09_homolog.pdf. Acesso em: 10 maio 2016>.

Presidência da República. Decreto N $N^{\circ}$ 7.611, de 17 de novembro de 2011. Dispõe sobre a educação especial, o atendimento educacional especializado e dá outras providências. Casa Civil; Subchefia para Assuntos Jurídicos, Brasília, DF, nov., 2011. Disponível em: <http://www.planalto.gov.br/ccivil_03/_ato20112014/2011/decreto/d7611.htm>. Acesso em: 10 maio 2016.

Lei $n^{\circ}$ 13.146, de 6 de julho de 2015. É instituída a Lei Brasileira de Inclusão da Pessoa com Deficiência (Estatuto da Pessoa com Deficiência), destinada a assegurar 
e a promover, em condições de igualdade, o exercício dos direitos e das liberdades fundamentais por pessoa com deficiência, visando à sua inclusão social e cidadania. Diário Oficial da União. Brasília, 7 jul. 2015. Disponível em: <http://www.planalto.gov.br/ccivil_03/_Ato2015-2018/2015/Lei/L13146.htm>. Acesso em: 10 maio 2016.

LÜDKE, M.; ANDRÉ, M. E. D. A. Pesquisa em educação: abordagens qualitativas. São Paulo: EPU, 1986.

SILVA, L. S. R. G. D. Inclusão: análise das práticas pedagógicas do ciclo alfabetização do ensino fundamental de escolas municipais de Limeira-SP. 2015. p. 130. Dissertação (Mestrado em Educação) - Instituto de Biociências, Universidade Estadual Paulista, Rio Claro, SP. 2015.

SILVA-PORTA, W. C. Prática pedagógica aos educandos com deficiência intelectual numa escola de ensino fundamental com alto IDEB. 2015. p. 184. Dissertação (Mestrado em Educação Especial) - Centro de Educação e Ciências Humanas, Universidade Federal de São Carlos, São Carlos, SP. 2015.

WISCH, T. F. Aprendizagem docente: o conhecimento compartilhado sobre inclusão e a formação continuada no ensino fundamental. 2013. p. 164. Dissertação (Mestrado em Educação) -Universidade Federal de Santa Maria, Santa Maria, RS. 2013.

\section{Como referenciar este artigo}

MORGADO, Camila Lourenço.; FISCARELL, Sílvio Henrique I. O processo de inclusão de uma aluna deficiente intelectual em uma escola comum do ensino fundamental I. Revista Ibero-Americana de Estudos em Educação, v. 11, n. esp. 2, p.956-968, 2016. Disponível em: <https://dx.doi.org/10.21723/riaee.v11.esp2.p956968>. E-ISSN: 1982-5587.

\section{Sobre os autores}

${ }^{\text {i }}$ Mestranda em Educação Escolar. UNESP - Universidade Estadual Paulista. Faculdade de Ciências e Letras - Pós-graduação em Educação Escolar. Araraquara - SP - Brasil. 14800-901 mila.morgado08@gmail.com.

ii UNESP - Universidade Estadual Paulista "Júlio de Mesquita Filho". Faculdade de Ciências e Letras de Araraquara. Departamento de Didática. Araraquara - SP - Brasil. 14800-901 